\title{
10
}

\section{Public Health Surveillance: A Vital Alert and Response Function}

\author{
Kumnuan Ungchusak, David Heymann, \\ and Marjorie Pollack
}

\section{Introduction}

A three-month delay in identifying the outbreak of Ebola virus in rural Guinea in late 2013 resulted in its rapid spread to urban areas and to neighbouring Liberia and Sierra Leone [1]. Once local and international responders identified the virus, they took a year to interrupt its widespread transmission. By April 2016, Ebola had accounted for more than 28,000 cases and over 11,000 deaths. People around the world watched with increasing alarm, as this tragic course of events played out, and with concern that air travel could enable the virus to spread across continents. This epidemic highlighted not only the inadequacy of local health systems to recognise and respond but also that international organisations were not ready to provide timely expertise and resources to control the situation and ameliorate the virus's spread through the region. Had health officials identified Ebola in West Africa promptly, they

The authors would like to thank Dr. Hugo López-Gatell, Dr. Vivek Singh and Dr. Pavana Murthy for their contributions to this chapter.

K. Ungchusak $(\bowtie)$

Thai Health Promotion Foundation, Bangkok, Thailand

D. Heymann

London School of Hygiene and Tropical Medicine, London, UK

M. Pollack

ProMED-mail, International Society of Infectious Diseases, Brookline, MA, USA 
could have minimised its impact on the lives and livelihoods of the populations of West Africa by implementing appropriate control procedures.

Public health officials coined the term surveillance to describe systems they set up to watch out for and control occurrence of health threats. Just as police, for example, set up closed-circuit television devices and community watch programmes to detect and prevent crime, public health surveillance systems engage all possible means to detect unwanted health events and prevent them from escalating and damaging population health. While public health surveillance originated to control spread of infectious diseases such as plague and cholera, it has evolved to include some non-communicable diseases, occupational health and injuries as well as surveillance of biological, behavioural and social determinants of these conditions.

We start by reviewing the public health need for surveillance and the development by the international community of regulations to control infectious diseases and other Public Health Emergencies of International Concern (PHEIC). We describe how epidemiologists use surveillance data to detect unusual events or outbreaks and to guide control programmes, and we provide guidance about maintaining data quality. We examine networks that contribute to global surveillance systems and highlight the role of social media and information technology in providing data to monitor new events of international importance. We consider challenges facing epidemiologists responsible for surveillance and describe efforts to address them.

\section{Public Health Surveillance: The Policy Imperative}

Public health surveillance is vital to the functioning of national and global health systems. Policymakers and health administrators need surveillance information to set priorities to address population health problems, allocate resources and monitor progress of prevention and control programmes; they need surveillance systems to alert them immediately of public health threats. Emerging infectious diseases, such as Avian influenza of different subtypes, Severe Acute Respiratory Syndrome (SARS) coronavirus, pandemic influenza H1N1 and the Zika virus (ZIKV) have the potential to spread rapidly causing severe loss of life and to impact socio-economic activity, especially trade and travel [2]. The outbreak of SARS in November 2002 highlighted the importance of every country having functioning and connected surveillance systems (see Box 10.1). 


\section{Box 10.1 The 2002-03 SARS Epidemic [3]}

SARS originated in wildlife and spread silently among humans as atypical pneumonia in Guangdong province, China, two months before officials became aware of it. Authorities began surveillance to identify atypical pneumonia cases but this, and the containment response, were too late to stop SARS spreading. A Chinese urologist who was infected travelled to Hong Kong and spread SARS to another 16 persons. Within weeks, SARS spread to 25 countries with more than 8,000 reported cases (Fig. 10.1) [3]. By the end of the epidemic in July 2003, SARS had killed 774 people [4]. Although unable to contain the outbreak of SARS, the international community was able to bring the epidemic under control within six months-by collaborating across countries to identify and isolate all probable cases. Nevertheless, the Asian Development Bank estimated that the economic loss due to SARS in affected countries was up to US $\$ 28$ billion with US\$ 5.8 billion on Mainland China (approximately 1.2 per cent of its annual gross domestic product (GDP)) and US\$ 6.6 billion in Hong Kong (approximately 4 per cent of its annual GDP) [5].

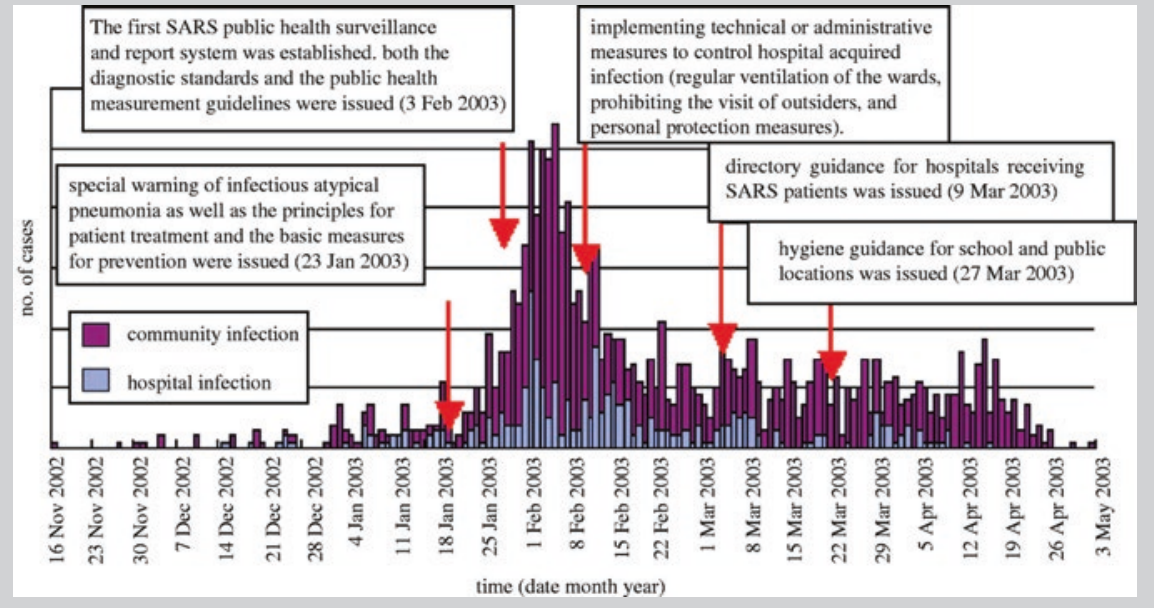

Fig. 10.1 Pattern of the 2002-03 SARS epidemic. (Source: Zhao [3])

Surveillance requires high-level government support, well-trained health workers, strong health information systems, well-functioning laboratories, effective communication systems and operational health facilities. To be effective, surveillance systems also require a strong legal framework to ensure that individual data can be shared while maintaining confidentiality as far as possible. Global cooperation between countries, with up-to-date international health agreements to build and maintain these capacities, is essential to decrease risk of international spread of infectious diseases and contain the risk of bio-terrorism. 


\section{Development of International Health Regulations: Rise of Global Surveillance}

Plague ravaged Europe during the fourteenth century and although authorities had no cure, they realised it was important to swiftly identify and isolate cases to prevent and control this lethal condition. Authorities understood that international spread of such diseases followed cross-border trade, pilgrimage and war; and so prevention of disease was a national security issue. In the city-state of Venice, authorities instigated quarantine measures-keeping arriving ships in the harbour for 40 days before docking, and holding people in isolation for 40 days at land borders to prevent entry of plague [6].

In the mid-nineteenth century, recognising that quarantine measures were not enough, governments agreed international conventions aimed at stopping spread of plague and cholera-and two other infectious diseases, yellow fever and smallpox. The conventions required each country to report outbreaks of these diseases to all signatories of the convention, and permitted application of certain public health measures at international borders once a country reported of one of the diseases. In the early twentieth century, governments in the Americas and in Europe set up regional conventions called International Sanitary Bureaus.

In 1951, the newly formed World Health Organization (WHO) led establishment of the International Sanitary Regulations (ISR) to foster global cooperation in reporting and acting at international borders to guard against spread of cholera, plague, yellow fever and smallpox.

In 1969, the WHO replaced the ISR with the International Health Regulations (IHR) which required countries to report any cases of cholera, plague, yellow fever and smallpox to WHO [7]. If a country reported one of these diseases, other countries could apply pre-established control measures at international borders - such as a requirement of proof of vaccination against yellow fever of any passenger arriving from a country that reported yellow fever to WHO.

Some countries reported to WHO late, or not at all, because of lack of capacity for public health surveillance, or because of fear of stigmatisation and economic repercussions. After HIV spread across international borders before being identified in 1981, the international community realised that infectious diseases could not be stopped at borders. Diseases often cross borders while still being incubated in humans, or in non-human hosts-insects, animals, and food and agricultural goods. In 2005, after the 2003 SARS outbreak, 
WHO updated and revised the IHR as a legal framework to include more diseases, and developed real-time evidence-based recommendations for prevention and control of outbreaks. WHO evaluates each newly identified outbreak for its potential to become a PHEIC by the country in which it is occurring.

The IHR 2005 mandate WHO member countries to report immediately the occurrence of a single case of four diseases (smallpox, poliomyelitis due to wild type poliovirus, human influenza caused by a new subtype, and SARS) [8]. Even though the world eradicated smallpox in 1980, the IHR still maintain it on the list to cover the risk of the virus escaping from a laboratory. Each country has an additional list of diseases that it requires its health workers to report by law. Diseases of greatest public health threat are reportable, meaning that health workers or laboratory technicians must report individual cases as they occur. Reportable diseases include those required by IHR and, for example, anthrax, cholera, Ebola, legionellosis, plague and the ZIKV. Other conditions are notifiable, meaning that health workers should report the number of cases that have occurred in a given time period. The number, frequency of reporting and breakdown of reportable and notifiable diseases varies by country. Diarrheal cases, influenza cases, tuberculosis, AIDS and other significant endemic diseases are usually required to be notified to local health authorities. In some countries the notifiable list can include non-infectious conditions such as maternal or infant deaths.

The IHR 2005 require countries to develop core capacities in public health, including surveillance systems and epidemiology services, that can analyse and act on surveillance information to detect and respond to diseases where and when they occur so that their potential to spread internationally is decreased.

\section{$4 \quad$ National Public Health Surveillance in Practice}

The purpose of surveillance activities is to: (1) detect at an early stage, acute public health threats from all hazards - biological, chemical, radiation, natural disaster and deliberate acts-which require rapid investigation and response; and (2) guide control programmes by measuring disease burden, monitoring trends, describing disease distribution and evaluating public health programme effectiveness (see Table 10.1).

The structure of government responsibilities for public health surveillance varies across countries. Most often, countries set up dedicated early warning 
Table 10.1 Framework for public health surveillance

\begin{tabular}{|c|c|c|}
\hline & $\begin{array}{l}\text { For early detection and rapid } \\
\text { response }\end{array}$ & To guide control programmes \\
\hline $\begin{array}{l}\text { Output } \\
\text { (purpose) }\end{array}$ & $\begin{array}{l}\text { Detection of outbreak, risk } \\
\text { assessment and alert, initiate } \\
\text { investigation, containment }\end{array}$ & $\begin{array}{l}\text { Ascertain magnitude, pattern, } \\
\text { distribution, forecast, monitor } \\
\text { and evaluate }\end{array}$ \\
\hline \multicolumn{3}{|l|}{ Process } \\
\hline Dissemination & Immediate, daily, weekly & Monthly, quarterly, annually \\
\hline Interpretation & Abnormal, clustering, outbreak & Trends, progress, gaps \\
\hline Analysis & \multicolumn{2}{|c|}{ Verification, frequency, distribution by time and place } \\
\hline Data collection & $\begin{array}{l}\text { Scanning, screening, } \\
\text { event-based }\end{array}$ & $\begin{array}{l}\text { Reporting, registration, surveys, } \\
\text { indicator-based }\end{array}$ \\
\hline Inputs & \multicolumn{2}{|c|}{$\begin{array}{l}\text { High-level government support, well-trained health workers, } \\
\text { strong health information systems, well-functioning laboratories, } \\
\text { effective communication systems, operational health facilities, } \\
\text { strong legal framework, financial resources, technologies, global } \\
\text { cooperation }\end{array}$} \\
\hline & \multicolumn{2}{|c|}{ Reports of notifiable diseases, media, rumours } \\
\hline
\end{tabular}

and rapid response surveillance teams that work with or complement surveillance activities of vertical control programmes such as malaria, HIV/AIDS or tuberculosis. Surveillance and response teams detect early stage public health threats while control programmes gather disease (or condition) specific information to plan activities. Control programmes share information with surveillance teams as required. A national network of public health laboratories, often linked to international reference laboratories, confirms etiologic agents, genetic strains and antibiotic resistance patterns. Surveillance activities are said to be active when health workers pro-actively seek out cases and passive when the system relies on patients to report themselves to a clinic.

\subsection{Surveillance Data to Detect Unusual Events or Outbreaks}

Using standard case definitions, health workers report individual cases of reportable and notifiable diseases to the local or national surveillance centre 
where staff aggregates reports, and clean and analyse the data. In cleaning the data, staff look for coding and classification errors, and for duplicate reports. Epidemiologists analyse the data to determine how many new cases have occurred during the past day or week and their distribution in time, place and by person to see whether the magnitude and pattern of the disease under surveillance is changing. They note any changes in frequency, clustering or distribution and flag them for verification and explanation. Box 10.2 illustrates how careful data analysis led to Malaysia identifying Nipah virus in 1999 [9].

\section{Box 10.2 Analysing Epidemiological Data to Identify Nipah Virus in Malaysia in 1999}

Japanese encephalitis commonly occurs in school-age children of both sexes. There is a seasonal pattern of disease related to the rainy season when transmission and therefore disease occurrence, increases; there is no difference in occurrence between ethnic or religious groups. From September 1998 to April 1999, surveillance teams sent reports of 229 cases of febrile encephalitis (48 per cent fatal) to the Malaysian Ministry of Health [9]. Initially, the ministry considered Japanese encephalitis virus to be the probable etiologic agent for this outbreak, and instituted conventional interventions of vaccination and insecticide to control mosquitoes. When they examined the surveillance data closely, the epidemiological pattern of encephalitis cases was different to what they expected-the disease occurred mostly among male adults of Chinese ethnic origin whose occupations related to pig farming. The ministry sought a different cause and found the etiologic agent to be a new paramyxovirus, later named Nipah virus.

Reporting of specific information about cases or patients or behaviour of populations under surveillance produces indicator-based data, that is individual or aggregated data derived from patients diagnosed-by syndrome description, clinical or laboratory confirmation — and identified through routine collection or active case search. The surveillance unit will also use eventbased data about outbreaks, unusual events or changes in human exposure [10]. Rather than wait for official reports, the surveillance team gathers information and rumours through the media, Internet and unusual events reported by the community, and investigates these reports. The team captures abnormal health events in real-time and confirms potential outbreaks by triangulating these data with indicator-based data.

Epidemiologists responsible for surveillance use standard epidemiological methods to analyse trends, identify clusters and investigate suspected risk factors (see Chap. 18 for an overview of epidemiological methods). For example, high numbers of reported cases of Kaposi Sarcoma among young men in New York and California during the early 1980s led to an investigation which showed a 
common risk factor of homosexual behaviour and its relationship with HIV/ AIDS [11]. Using increasingly sophisticated technologies for data capture and analysis, surveillance teams can monitor real-time occurrence, in time and place, of unusual events such as cholera or legionella, or seasonal outbreaks such as malaria (see Chap. 20 for an introduction to spatial and spatio-temporal techniques and to Chap. 14 which discusses predicting climate-related health outcomes such as malaria).

Once epidemiologists have concluded their analyses (sometimes in realtime), they prepare reports which can trigger immediate action by a rapid response team to visit the site of the events, investigate the situation and contain the outbreak. The team also sends reports to clinicians in hospitals and to local and national programme managers. Many countries publish weekly disease surveillance reports that are also available to the general public: for example, the US Centers for Disease Control and Prevention (CDC) publish the Morbidity and Mortality Weekly Report (MMWR) [12], the European Centre for Disease Control (ECDC) publishes Eurosurveillance [13], and the WHO publishes the Weekly Epidemiological Record [14]. Box 10.3 shows how epidemiologists associated microcephaly with ZIKV which led WHO to declare ZIKV a PHEIC [15].

\section{Box 10.3 Evidence to Identify the Zika Virus as a Public Health Event of International Concern [15]}

In late 2015, ZIKV spread rapidly through Latin America especially in Brazil and El Salvador. Surveillance of birth defects in Brazil identified a major increase in microcephaly during the period when ZIKV transmission increased. This alerted policymakers and epidemiologists to study whether the increase in birth defects was associated with ZIKV infection during pregnancy. WHO declared the suspected increase in microcephaly in association with ZIKV infection of pregnant women a PHEIC and recommended pregnant women to protect themselves from mosquito bites and to avoid travel to areas with known ZIKV transmission. The observation that men who travelled to areas with known ZIKV transmission could sexually transmit ZIKV to their partners led WHO to recommend practising safer sex or abstinence for a period of six months for men and women returning from areas of active transmission.

\subsection{Surveillance Data to Guide Control Programmes}

Public health surveillance guides control programmes by undertaking the following functions: 
Measuring the Occurrence and Burden of a Disease or Condition, and Describing Its Epidemiological Patterns Disease in humans results from interactions between the human host and causative agents or hazards of all types. The natural and socio-economic environment influences these interactions. Diseases usually occur in the same pattern when there is no change in the causative agent (such as mutation), in the human host (such as vaccination) or in the environment (such as climate change). A surveillance system can closely monitor any changes in these dynamic factors and their consequences, as illustrated by the case of Nipah virus in Malaysia (Box 10.1).

Monitoring and Forecasting Trends in Risk Behaviour Public health surveillance must also address risk. For example, surveillance of annual per capita cigarette consumption in the US showed an increased trend from 54 cigarettes in 1900 to 4,345 cigarettes in 1963. Researchers related this trend to advertising and an expansion in the number of cigarette companies. In 1998, after the first studies suggesting cigarette consumption was related to lung cancer, and the US Surgeon General issued a warning, the annual per capita consumption decreased to 2,261 [16]. With surveillance information, epidemiologists can forecast an increase in lung cancer without intervention thereby providing evidence for policy to implement effective interventions such as taxation to prevent smoking.

Evaluating Performance of Control Programmes After they have implemented interventions, health authorities use surveillance data to see if disease incidence declines. For example, when vaccine coverage increases, the number of cases of vaccine preventable diseases is expected to decrease. Increasing taxes on cigarettes is one way to reduce consumption. Surveillance data can document a correlation between increasing taxes and decreasing trends in cigarette consumption.

To achieve these functions, programme managers collect data through patient records, surveys, programme records or informal sources. Types of data include determinants of the condition, behaviours or risk factors associated with the condition, morbidity and mortality associated with the condition, programme responses, and abnormal or unusual events associated with the condition. Table 10.2 provides examples of these types of data for surveillance of an HIV/AIDS control programme. 


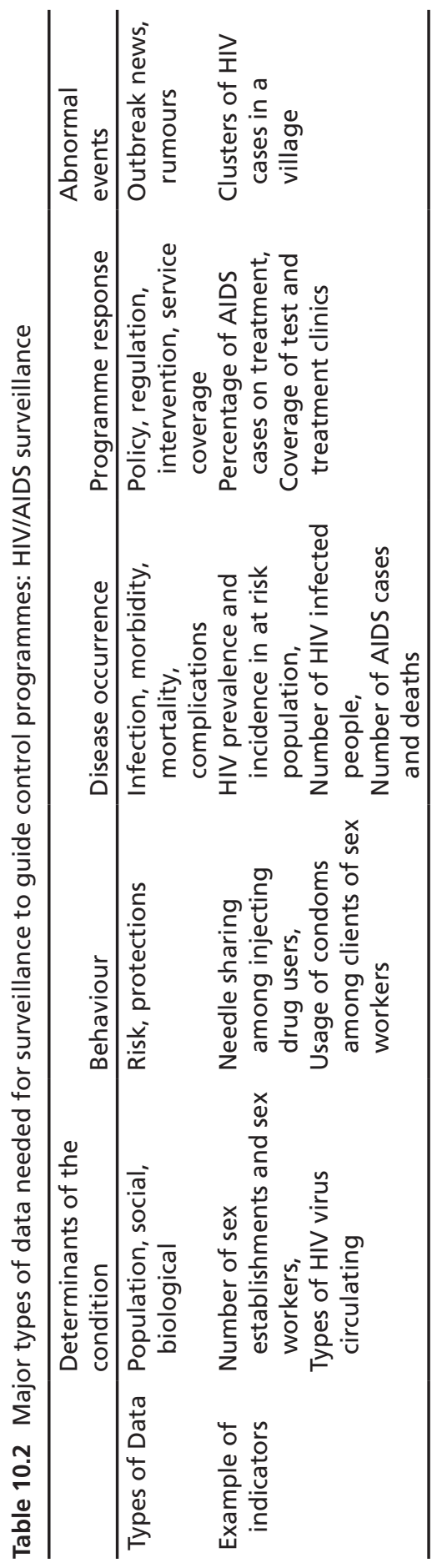




\subsection{Maintaining Standards by Reviewing Surveillance Systems}

To ensure surveillance programmes have adequate resources and produce useful information, public health authorities regularly review their surveillance activities. In 1988, the US CDC issued guidelines to evaluate surveillance systems which, with some updating, are still widely used [17]. These guidelines focus evaluation of public health surveillance on three areas: (1) the surveillance system itself, describing the system, its structure, diseases under surveillance, sources of data, and how data are processed, analysed and disseminated; (2) the resources used to operate the system, including funding sources, adequately trained staff and information technology; and (3) the usefulness and quality of surveillance information, using the following indicators:

Usefulness of Data Do the data and information disseminated to data providers and users contain comprehensible facts and findings and useful recommendations to improve control measures and guide programme management? Has the system detected outbreaks? How many of the detected outbreaks were investigated and controlled in a timely manner?

Timeliness of Data and Other Information Is data dissemination timely and regular? For example, epidemic prone diseases require weekly summary, while other diseases require only monthly or quarterly summaries. Are these requirements met?

Validity and Completeness of Data Much of the data come from clinical diagnoses that do not have laboratory confirmation. It is useful to conduct studies to determine the accuracy of diagnoses using standard laboratory confirmation testing. This helps in preparing estimates of the proportion of confirmed cases among all reported cases. When undertaking field investigations, investigators can compare the number of actual cases they find with the number of cases reported through the system. This provides an estimate of reporting completeness of the system. 


\section{$5 \quad$ Global Public Health Surveillance}

Global public health surveillance is the collection, analysis and use of standardised information about health threats or their risk factors from more than one country, and usually worldwide. While surveillance mainly focuses on infectious diseases, global systems also seek to identify deliberate use of biological agents or toxins to cause harm.

WHO leads the global public health surveillance system, gathering information from formal and informal sources working through its country and regional offices. WHO extends its reach through the Global Outbreak and Response Network (GOARN) [18] which comprises over 120 national technical institutions that support WHO to detect public health threats and respond to outbreaks. WHO uses the information for risk assessment and analysis as part of its routine disease control and prevention programme activities. When requested by countries for support, WHO works with GOARN institutions to recruit suitable experts. GOARN includes regional networks of countries that cooperate independently to prevent and control infectious diseases occurring in their regions, for example, the East African Integrated Disease Surveillance Network (EAIDSNet), [19] and the Mekong Basin Disease Surveillance network (MBDS) [20].

WHO leads global networks that work to control specific diseases. These networks depend on cooperation of governments, public health workers and scientists to report cases, provide specimens and share information so that specific diseases can be controlled globally. These include:

\section{Networks to Support Influenza Control Through Vaccine Development The} Global Influenza Surveillance and Response System (GISRS) consists of national sentinel centres and national and regional laboratories which annually collect 200,000-250,000 nasal swabs from patients presenting with influenza-like illness. Their analyses provide information about the distribution of strains circulating each year and enable scientists to recommend the influenza vaccine composition for the following year based on predominant sequences. GISRS also uses FluNet, a public web-based data collection and reporting tool that tracks movement of influenza viruses globally and provides epidemiological data about influenza outbreaks [21].

Networks to Inform Polio Eradication The Global Polio Laboratory Network (GPLN) [22] underpins the Global Polio Eradication Initiative. Clinical health workers and epidemiologists report all cases of acute flaccid paralysis 
(AFP) in children under 15 years of age from whom they have collected stool specimens for isolation and identification of the poliovirus. Through its network of national, regional and specialised laboratories, GPLN determines whether polio was the cause of the AFP, genetically sequences viruses and compares them to a global database to understand their geographic source. If a polio virus is found, GPLN informs the national authority and WHO regional office for appropriate action.

Networks to Support Control of Anti-Tuberculosis Drug Resistance The Global Project on Anti-Tuberculosis Drug Resistance Surveillance [23] is a common surveillance platform to which countries can provide data that are then used to monitor the evolution and spread of multi-drug resistant tuberculosis (MDR-TB) and extensively drug-resistant tuberculosis (XDR-TB). National laboratories provide susceptibility testing of tuberculosis organisms collected from patients, supported by a supranational tuberculosis reference laboratory network. The Global Project provides understanding of the prevalence and distribution of tuberculosis resistance worldwide.

Networks to Gain Information About the Spread of Anti-Microbial Resistance (AMR) WHO runs the Global Antimicrobial Resistance Surveillance System (GLASS) [24]. Its goal is to develop a standardised strategy to collect, analyse and share clinical, laboratory and epidemiological data globally, assess the burden and support local, national and global strategies to control AMR.

\section{The Role of Information and Communication Technology in Surveillance}

Until recently, surveillance systems depended on paper-based reporting, compilation and analysis of data. Computers and electronic reporting have made compilation and analysis of data much easier, and the World Wide Web (WWW) and the Internet improve the comprehensiveness of reporting. Digital and internet-based technology can retrieve information from medical records on a daily basis - but this must be done without infringing personal privacy. Hospitals, especially private ones, may refuse to provide patient information to the public health sector unless privacy issues are addressed.

Cell phone technology has extended the scope of informal and event-based surveillance while social media has transformed exploring rumours of new events. Some ground-breaking examples of the use of information and communication technology include: 
Electronic Reporting of Events The Programme for Monitoring Emerging Diseases (ProMed-mail) is a fully moderated internet-based listserv, that receives and publishes reports of public health events in humans, animals, wildlife and plants from its subscribers and other traditional and nontraditional information sources [25]. ProMed-mail uses information available on the WWW and from voluntary listserv reporters who actively search for and report public health events in realtime from the media, Internet blogs and other sites. ProMed-mail editors and expert moderators review, analyse, evaluate and where possible validate reports, and then disseminate them to listserv members and post them on its website.

Using Big Data to Identify Events The subscription-based application Global Public Health Intelligence Network (GPHIN) continuously scans the WWW gathering information from multiple source news aggregators in real-time [26]. GPHIN searches in nine languages for key words that could indicate infectious disease outbreaks, or environmental, radioactive and natural disasters. Analysts identify new events and inform subscribers-who are governmental and non-governmental agencies with an established public health mandate. Every 24 hours, analysts communicate new information to WHO which validates reports through its network of regional and country offices. WHO discusses events that it validates in confidence with health departments in the countries involved.

Mapping Events in Real-Time HealthMap, a fully automated application, utilises online informal sources for disease outbreak monitoring and real-time surveillance of emerging public health threats [27]. HealthMap trawls WWW sources of information (in nine languages) including online eyewitness reports, expert-curated discussions such as ProMed-mail, validated official reports, for example from WHO, or the Food and Agriculture Organization of the United Nations, and news aggregation services such as Google News. Using open source software, HealthMap displays the events by time, geographic location and aetiology.

Participatory Flu Tracking Diseases and abnormal events happen all the time in the community. Only some patients, especially those presenting with severe disease manifestations, seek medical care. Flu Near You invites anyone living North America, over 12 years of age, to report if they have an influenza-like illness [28]. Once registered, participants are asked weekly by e-mail to complete a brief survey that seeks information on ten symptoms linked to influ- 
enza, and other information such as whether or not the registered participant has had an influenza vaccination. Other countries, including the UK, have adopted similar participatory influenza surveillance systems, thereby adding a greater understanding of the epidemiology of influenza around the world.

Participatory Onehealth Disease Detection (PODD) Chang Mai University in Thailand, with support from the Skool Foundation, developed this mobile application which connects 296 volunteers in 71 local governments. When volunteers notice an abnormal event such as poultry dying off or sickness in animals or humans, they use PODD to notify local authorities who dispatch a surveillance and rapid response team to investigate and contain the event. After 16 months of implementation, PODD has enabled the detection of 1,029 abnormal events, including 26 chicken high-mortality outbreaks, four cattle disease outbreaks, three pig disease outbreaks and three fish disease outbreaks, all of which were detected and controlled [29].

\section{Challenges and the Future}

Since revision of the IHR in 2005, outbreaks due to infections, including the Middle East Respiratory Syndrome coronavirus and Ebola virus, have highlighted continued weaknesses in public health surveillance and response capacities in most countries, with international spread causing disruptions in trade and travel, and negatively impacting economies. We present some challenges and suggest some solutions.

\subsection{Coordination of National Surveillance Activities}

Most countries have established disease control programmes each with a surveillance component reporting from grassroots through provincial and national levels. National surveillance units may have sufficient staff for each disease control programme, but at lower levels of the health system, the same individuals often manage more than one programme and are heavily burdened by reporting requirements. There is also duplication of effort in reporting between programmes. WHO supports countries to coordinate surveillance activities across departments, programmes and administrative levels through Integrated Disease Surveillance and Response (IDSR) [30]. IDSR links surveillance with other health information activities and strengthens overall capacity of countries to maintain public health surveillance. 


\subsection{Building Capacity for a National Surveillance System}

The IHR 2005 obligates countries to develop comprehensive disease surveillance, detection and response when and where infectious diseases and other acute public health threats occur. In reality, national surveillance capacity in many countries is still not at expected and necessary levels. This may be, as the Ebola epidemic demonstrated in West Africa, that health systems are weak and under-funded, or that the surveillance system itself does not function efficiently. Regular evaluation of the system, as we describe in Sect. 4.3, can identify which components need to be strengthened. An over-riding issue is for the system to deploy and maintain enough professionals throughout the system with the required skills — understanding the nature and limitations of the data they are working with and able to interpret and draw important findings from the analyses of the surveillance data. Since the US CDC initiated the Epidemic Intelligence Services (EIS) in 1951, other regions of the world have established similar training programmes and are graduating field-based epidemiologists with expertise in surveillance and response. Currently, there are 69 such programmes around the world forming the Training Programs in Epidemiology and Public Health Interventions Network (TEPHINET) [31].

\subsection{Coordinating Surveillance Across Sectors}

Approximately 75 per cent of newly identified human diseases are zoonotic in origin [32] and 70 per cent of these diseases have their origins in wildlife [33]. Since the 1997 outbreak of H5N1 Avian Influenza in Hong Kong, animal surveillance and human surveillance units have begun to share information and alert each other of unusual events. Environmental factors are also crucial to disease occurrence, for example, paralytic shellfish poisoning among people who consume shellfish affected by harmful algae growth in the sea [34]. The One Health approach involves sharing information between multiple health sectors and working together to identify and resolve outbreaks [35].

\subsection{Sharing Information and Ensuring Equal Benefit}

During the 2005 Avian Influenza outbreak, WHO requested all affected countries to share the virus isolated from humans for further study and vaccine development. Some governments expressed concern about potential negative economic consequences of sharing information and about 
possible inequities in the benefits of sharing. This led to the 2007 Jakarta Declaration on responsible practices for sharing Avian Influenza viruses and resulting benefits [36]. This declaration underlined need for continued open, timely and equitable sharing of information, data and biological specimens related to influenza; it also emphasised need for more equitable sharing of benefits for example in the generation of diagnostics, drugs and vaccines. The Jakarta Declaration led to the Pandemic Influenza Preparedness Framework (PIP) under which manufacturers of influenza vaccines, diagnostics and pharmaceuticals that use GISRS information make annual financial contributions to WHO. WHO uses approximately 70 per cent of these contributions for pandemic preparedness activities and surveillance, and 30 per cent for pandemic response including purchase of vaccines and antivirals at the time of a pandemic for countries without access to these supplies.

In May 2017, the Chatham House Centre on Global Health Security, after a series of roundtable consultation with experts in public health surveillance, produced a guide on Strengthening Data Sharing for Public Health Surveillance. This guide facilitates both informal and formal data sharing. The guide proposes seven principles: building trust; articulating the value; planning; using quality data; understanding the legal context; coming to agreement; and evaluating. The guidelines help create the right environment for data sharing and to facilitate good practice in addressing technical, political, ethical, economic and legal concerns that may arise. The guidelines aim to ensure, to the greatest extent possible, that any benefits arising from use of the data are shared equitably [37].

\subsection{Ethical Issues in Public Health Surveillance}

Similar to clinical or public health practice, institutions or agencies responsible for public health surveillance need a set of ethical principles to guide their operations. The $2017 \mathrm{WHO}$ guidelines on ethical issues in public health surveillance proposed 17 guidelines [38]. These guidelines fall into three major groups: first, the mandate and broad responsibility of the agency to undertake surveillance and subject it to ethical scrutiny; second, the obligation to ensure appropriate protection and rights of individuals under surveillance; and third, considerations in making decisions about how to communicate and share surveillance data to pursue common good and equity of population without harm to individual. 


\section{Conclusion}

The West African Ebola outbreak provided a costly lesson that policymakers must commit to establishing, maintaining and advancing public health surveillance systems to protect and promote population health. To prepare for the next major outbreak, the world needs to invest in a strong warning and response system led by a global institution with sufficient authority and funding to react swiftly [39]. WHO serves this role but is chronically underfunded. Similar investment is needed in countries where a fully supported, well-functioning surveillance office or programme must coordinate different components of the surveillance system. Surveillance information should be disseminated widely to alert the public and health programmes of outbreaks so that they can contain the disease at source before it spreads internationally. Because the world urgently needs reliable and timely surveillance information, public health surveillance should continue to make innovative use of new technology to gather and share information strategically and fairly.

\section{Key Messages}

- The 2014 Ebola outbreak highlighted inadequacies of national and global surveillance systems to detect and respond to public health threats.

- Surveillance provides critical data and information to guide, improve and protect public health.

- More trained staff are needed for effective and efficient surveillance especially in low- and middle-income countries.

- Innovative use of information technology and social media can aid detection of public health threats.

\section{References}

1. World Health Organization. One year into the Ebola epidemic: a deadly, tenacious and unforgiving virus: World Health Organization. 2015 [cited 2017 12th December]. Available from: http://www.who.int/csr/disease/ebola/one-yearreport/ebola-report-1-year.pdf?ua $=1$

2. Morens DM, Fauci AS. Emerging infectious diseases in 2010. 20 years after the Institute of Medicine report. mBio. American Society for Microbiology; 2012 Dec 11;3(6). Available from: http://dx.doi.org/10.1128/mbio.00494-12

3. Zhao G -p. SARS molecular epidemiology: a Chinese fairy tale of controlling an emerging zoonotic disease in the genomics era. Philosophical Transactions of the 
Royal Society B: Biological Sciences. 2007 Jun 29;362(1482):1063-81. Available from: http://dx.doi.org/10.1098/rstb.2007.2034

4. Mackenzie J, Merianos A. The legacies of SARS - international preparedness and readiness to respond to future threats in the Western Pacific Region. Western Pacific Surveillance and Response Journal. 2013 Jul 2;4(3):4-8. Available from: http://dx.doi.org/10.5365/wpsar.2013.4.2.009

5. Fan EX. SARS economic impacts and implications. Economic and Research Department Policy Brief No 15. Asian Development Bank. [cited 2018 14th January]. Available from: https://www.adb.org/sites/default/files/publication/28073/ pb015.pdf

6. Tognotti E. Lessons from the history of quarantine, from plague to influenza A. Emerging Infectious Diseases. 2013 Feb;19(2):254-9. Available from: http:// dx.doi.org/10.3201/eid1902.120312

7. World Health Organization. The International Health Regulations. Adopted by the World Health Assembly in 1969. 1969 [cited 2017 12th December]. Available from: https://www.who.int/ihr/current/en/

8. World Health Organization. International Health Regulations (2005): World Health Organization. 2008 [cited 2017 12th December]. Available from: http:// www.who.int/ihr/9789241596664/en/

9. Outbreak of Hendra-Like Virus-Malaysia and Singapore, 1998-1999. Journal of the American Medical Association. 1999 May 19;281(19):1787. Available from: http://dx.doi.org/10.1001/jama.281.19.1787-jwr0519-2-1

10. World Health Organization. Early detection, assessment and response to acute public health events: implementation of early warning and response with a focus on event-based surveillance: interim version WHO/HSE/GCR/LYO/2014.4. 2014 [cited 2017 12th December]. Available from: http://apps.who.int/iris/bitstream/10665/112667/1/WHO_HSE_GCR_LYO_2014.4_eng.pdf

11. Cancer Research UK. Kaposi Sarcoma and AIDS. [cited 2018 13th January]. Available from: http://scienceblog.cancerresearchuk.org/2010/01/22/high-impactscience-kaposi-sarcoma-and-aids-unravelling-a-medical-m

12. Centers for Disease Control and Prevention. Morbidity and Mortality Weekly Report (MMWR) [cited 2017 12th December]. Available from: https://www. cdc.gov/mmwr/index.html

13. European Centre for Disease Prevention and Control. Eurosurveillance. 2017 [cited 2017 12th December]. Available from: http://www.eurosurveillance.org/ content/eurosurveillance/browse

14. World Health Organization. Weekly Epidemiological Record (WER) [cited 2018 5th November]. Available at: https://www.who.int/wer/en/

15. World Health Organization. WHO Director-General summarizes the outcome of the Emergency Committee regarding clusters of microcephaly and GuillainBarré syndrome. 2016 [cited 2017 12th December]. Available from: http:// www.who.int/iris/handle/10665/112667 
16. Centers for Disease Control and Prevention. Achievements in public health, 1900-1999: Tobacco use-United States, 1900-1999. Morbidity and Mortality Weekly Report. 1999;48(43):986-93. [cited 2018 5th November]. Available from: https://www.cdc.gov/mmwr/preview/mmwrhtml $/ \mathrm{mm} 4843 \mathrm{a} 2 . \mathrm{htm}$

17. German RR, Lee L, Horan J, Milstein R, Pertowski C, Waller M. Updated guidelines for evaluating public health surveillance systems. Morbidity and Mortality Weekly Report. 2001;50(1-35). [Cited 2018 5th November]. Available from: https://www.cdc.gov/mmwr/preview/mmwrhtml/rr5013a1.htm

18. Mackenzie JS, Drury P, Arthur RR, Ryan MJ, Grein T, Slattery R, et al. The global outbreak alert and response network. Global Public Health. 2014 Sep 4;9(9):1023-39. Available from: http://dx.doi.org/10.1080/17441692.2014.951 870

19. East African Community. East African Integrated Disease Surveillance Network. [cited 2018 13th January]. Available from: https://www.eac.int/health/diseaseprevention/east-african-integrated-disease-surveillance-network

20. Mekong Basin Disease Surveillance Network. [cited 2017 12th December]. Available from: http://www.mbdsnet.org/

21. World Health Organization. FluNet. 2017 [cited 2017 12th December]. Available from: http://www.who.int/influenza/gisrs_laboratory/flunet/en/

22. Global Polio Laboratory Network. 2017 [cited 2017 12th December]. Available from: http://polioeradication.org/polio-today/polio-now/surveillance-indicators/the-global-polio-laboratory-network-gpln/

23. World Health Organization. Surveillance of drug resistance in tuberculosis. [cited 2017 12th December]. Available from: https://www.cdc.gov/mmwr/ index.html

24. World Health Organization. Global Anti-microbial Resistance Surveillance System (GLASS). [cited 2017 12th December]. Available from: http://www. who.int/antimicrobial-resistance/global-action-plan/surveillance/glass/en/

25. International Society for Infectious Diseases. ProMed Mail. [cited 2017 12th December]. Available from: http://www.promedmail.org/

26. World Health Organization. Epidemic intelligence - systematic event detection. 2017 [cited 2017 12th December]. Available from: http://www.who.int/csr/ alertresponse/epidemicintelligence/en/

27. HealthMap. [cited 2017 12th December]. Available from: http://www.healthmap.org/en/

28. Flu Near You. [cited 2018 13th January]. Available from: https://flunearyou. org/ - !/

29. Srikitjakarn L. PODD: An innovative one health surveillance system preventing pandemics with animal origins. 2017 [cited 2017 12th December]. Available from: http://www.icts13.chiangmai.cmu.ac.th/pdf_roundtable_abstract.php?rtb_id=101

30. World Health Organization. Integrated disease surveillance. 2017 [Available from: http://www.who.int/csr/labepidemiology/projects/diseasesurv/en/ 
31. TEPHINET. Training Programs in Epidemiology and Public Health Interventions Network. [cited 2017 12th December]. Available from: http:// tephinet.org/programs

32. Taylor LH, Latham SM, Woolhouse MEJ. Risk factors for human disease emergence. Philosophical Transactions of the Royal Society B: Biological Sciences. 2001 Jul 29;356(1411):983-9. Available from: http://dx.doi.org/10.1098/ rstb.2001.0888

33. Jones KE, Patel NG, Levy MA, Storeygard A, Balk D, Gittleman JL, et al. Global trends in emerging infectious diseases. 2008 Feb;451(7181):990-3. Available from: http://dx.doi.org/10.1038/nature06536

34. Woods Hole Oceanographic Institution. Harmful algae. [cited 2017 12th December]. Available from: https://www.whoi.edu/redtide/home

35. One Health Initiative. One Health Initiative will unite human and veterinary medicine, [cited 2017 12th December]. Available from: http://www.onehealthinitiative.com/

36. Eur Bali. Jakarta Declaration on Virus Sharing: a strategic step to more equitable and affordable Avian Flu vaccines Distribution. [cited 2017 12th December]. Available from: http://www.eurobali.org/index.php?action=news\&category_ id $=58$ news_id $=190$

37. Centre on Global Health Security. A Guide to sharing the data and benefits of public health surveillance. London (UK): The Royal Institute of International Affairs Chatham House; 2017. p. 46. [cited 2018 5th November]. Available from: https://www.chathamhouse.org/sites/default/files/publications/research/201705-25-data-sharing-guide.pdf

38. World Health Organization. WHO guidelines on ethical issues in public health surveillance. [cited 2017 12th December]. Available from: http://www.who.int/ ethics/publications/public-health-surveillance/en/

39. Gates B. The next epidemic - lessons from Ebola. New England Journal of Medicine. 2015 Apr 9;372(15):1381-4. Available from: http://dx.doi.org/10.1056/ nejmp1502918 